\title{
Recurrent Paronychia as a Presenting Manifestation of Pemphigus Vulgaris: A Case Report
}

\author{
Vijay Zawar Manoj Pawar Shrikant Kumavat
}

Skin Disease Centre, Nashik, India

\section{Established Facts}

- Pemphigus vulgaris with nail involvement is known, and paronychia is the most common manifestation of the disease.

\section{Novel Insights}

- Recurrent paronychia can be the initial presentation of pemphigus vulgaris in certain patients.

\section{Keywords}

Paronychia · Pemphigus vulgaris · Prednisolone ·

Azathioprine

\begin{abstract}
Nail involvement in pemphigus vulgaris (PV) is an unusual clinical finding. The most common clinical manifestations include chronic paronychia and onychomadesis. We report an adult female patient with PV who initially presented with chronic paronychia of multiple fingernails and toenails before the onset of vesiculobullous eruptions. Later on, after complete resolution, there was recurrence of pemphigus presenting as hemorrhagic paronychia of the left index finger. Systemic treatment with corticosteroids and azathioprine led to complete resolution of mucocutaneous lesions as well as nail manifestations. Thus, chronic treatment-resistant paronychia may be an early and important sign of generalized pemphigus in certain patients.

(c) 2017 S. Karger AG, Basel
\end{abstract}

\section{Introduction}

Pemphigus vulgaris (PV) is an autoimmune mucocutaneous vesiculobullous disease [1]. It is characterized by intra-epidermal bullae with suprabasal acantholysis and IgG autoantibody to the desmosomal adhesion protein desmoglein 3 (Dsg3) and sometimes desmoglein 1 (Dsg1) [2]. It usually occurs between the 4 th and 6 th decades of life $[3,4]$. Nail involvement in PV is relatively uncommon, and it is taken as an indicator of the severity of the pemphigus [5]. It can lead to a diagnostic dilemma, especially if there are no other clinical signs suggestive of PV.

\section{Case Report}

A 55-year-old Indian housewife presented with a symmetric painful swelling of the proximal and lateral nail folds of all fingers of both hands, except the little fingers, and also of the 1st and 2 nd toes of both feet of 3 months' duration with serosanguinous dis-

\section{KARGER}

(c) 2017 S. Karger AG, Basel

E-Mail karger@karger.com

www.karger.com/sad
Dr. Manoj Pawar, MD

Flat No.11, Manomay Apartment, Khande mala

Savatanagar, CIDCO

Nashik 422008 (India)

E-Mail manojpawar624@yahoo.com 


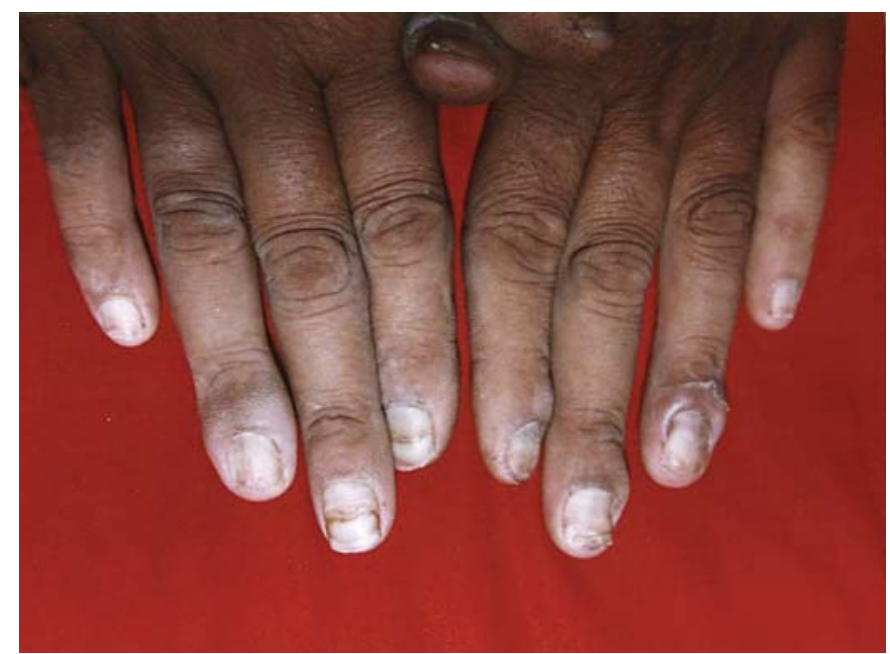

Fig. 1. Suppurative inflammation over the proximal and lateral nail folds of the first 4 fingers of both hands, with Beau's lines, on the first visit.

charge (Fig. 1). She had been treated with multiple courses of topical as well as oral antibiotics without any improvement at various other centers. She came to us for consultation when she noticed the sudden onset of vesiculobullous eruptions over her back and soreness in the oral cavity. On examination, suppurative inflammation was noted over the proximal and lateral nail folds of the first 4 fingers of both hands and of the 1st and 2nd toes of both feet, accompanied by Beau's lines. Oral cavity examination showed confluent erosions and denuded epithelium on the upper and lower lips and over the hard palate. A few conjunctival erosions were also noted. Gram stain and potassium hydroxide preparations of the drainage from the nails were inconclusive; bacterial and fungal cultures of the same revealed no growth. Skin biopsies of the paronychial areas and of the perilesional skin of the vesiculobullous rash on the trunk revealed suprabasal cleft and acantholysis. Direct immunofluorescence of the perilesional skin showed epidermal intercellular deposition of IgG and C3 in a fishnet pattern. Indirect immunofluorescence showed antibodies to Dsg3 and Dsg1 with a titer of 1:40. A diagnosis of PV was established, and after thorough screening she was treated with oral prednisolone at an initial dose of $1 \mathrm{mg} / \mathrm{kg} / \mathrm{day}$, which was gradually tapered, and oral azathioprine $50 \mathrm{mg} /$ day was added thereafter. During the follow-up of 6 months, all cutaneous and mucosal lesions resolved within 2 months, while the nail lesions were slower to resolve but certainly showed marked improvement (Fig. 2). At this point of time, she was lost to follow-up.

Eight months later, she again came back with painful paronychia, subungual hemorrhage, and brittle nail of the left index finger (Fig. 3). For the last 6 months, she had stopped all drugs which she had been given for PV, and the onset of paronychia was spontaneous. Clinical examination revealed erosions in the oral cavity and conjunctivae. Gram stain, Ziehl-Neelsen stain, Tzanck smear, and potassium hydroxide preparation from the nail lesions were negative. She was again treated with a high dose of oral prednisolone and azathioprine. Oral, conjunctival, and nail lesions completely resolved within the next 2 months. The patient remained asymptomatic at a further 6-month follow-up.

Paronychia - A Presenting Manifestation of Pemphigus

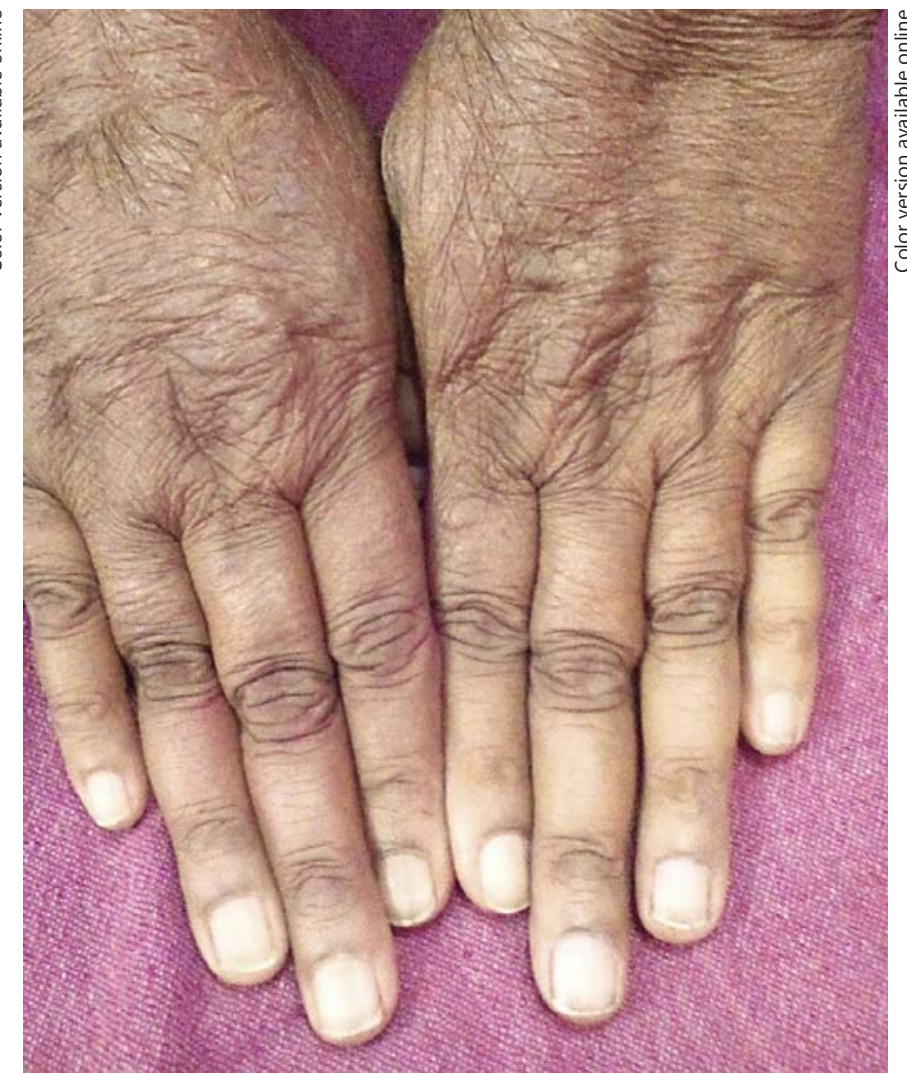

Fig. 2. Resolution of paronychial changes of the hands after treatment.

\section{Discussion}

$\mathrm{PV}$ is an autoimmune vesiculobullous disease which mainly involves the skin and mucosae. Nail changes as a presenting manifestation of PV are quite rare. Engineer et al. [5] summarized all reports of PV with nail involvement in the English literature and noted paronychia (60\%) as the most common finding followed by onychomadesis (33\%) in 15 patients. A study by Schlesinger et al. [6] noted nail changes in 47\% (30 of 64) of patients with PV. Another study by El-Komy et al. [7] on 25 patients with PV showed onycholysis and subungual hyperkeratosis in 16 patients (64\%) as the most common nail alterations.

However, nail changes as a presenting manifestation of PV are quite unusual. In our patient, the initial presentation was chronic paronychia of multiple nails, and interestingly, recurrence also presented as hemorrhagic paronychia of the left index finger.

Nail disease can be a part of the initial presentation along with mucosal and cutaneous lesions, can precede a

Skin Appendage Disord 2017;3:28-31 
Fig. 3. Relapse of pemphigus vulgaris presenting as paronychia, subungual hemorrhage, and brittle nail of the left index finger.

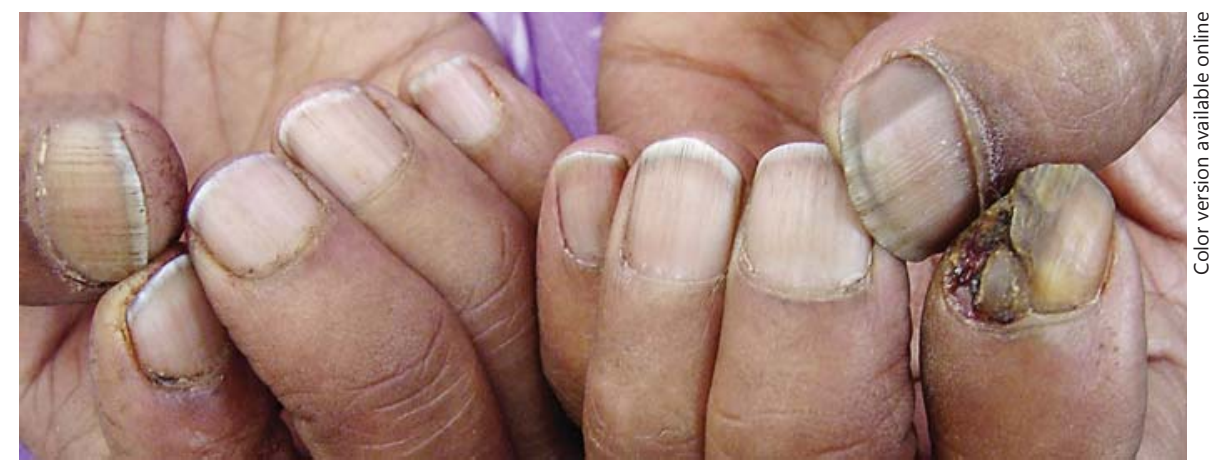

flare of the pre-existing disease, or can be the only sign of the disease [5-13]. It manifests as chronic paronychia, onychomadesis, Beau's lines, trachyonychia, onycholysis, subungual hemorrhage, nail plate discoloration, pitting, onychoschizia, and nail dystrophy [6-19]. Pseudopyogenic granuloma of the proximal or lateral nail fold can also be seen, and it has been reported to be the first symptom of a relapse of the disease [20]. According to Habibi et al. [21], these nail changes are related to the number of skin bullae and the presence of periungual bullae. Depending on the location of acantholysis in the nail folds, different nail changes may result. Dorsal nail fold involvement leads to acute periungual inflammation and bullous lesions, while ventral nail fold disease changes are subtle and indistinguishable from those of chronic paronychia. Nail matrix damage as a result of periungual inflammation results in Beau's lines, onychomadesis, onychoschizia, cross-ridging, pitting, and trachyonychia. Habibi et al. [21] noted these signs in one-third of patients with PV. Subungual bullae cause nail bed detachment with onycholysis, which is often hemorrhagic and heralds a poor prognosis in patients with PV [22].

There are likely to be anatomical, structural, and molecular differences in epithelial structures of the nail bed, matrix, and nail fold compared to the epithelial structures of the skin and mucosa. One of the hypotheses explaining the paucity of nail involvement in PV is the relative sequestration of the autoantigen from the immune system in the "immunologically privileged" site of the nail. This area of relative "immune privilege" in the proximal nail matrix constitutes a safeguard against autoimmunity. The number and function of antigen-presenting cells are substantially lower in the nail immune system than in the cutaneous or mucosal epidermis [5, 19]. Also, there is a downregulation of major histocompatibility class II and CD209 expression by Langerhans cells in the proximal nail matrix with reduced function and/or number of nat-

ural killer and mast cells around the human nail apparatus [19].

The nail matrix is devoid of a granular layer, and the nail bed epidermis is 2-3 cells thick [23]. Hence, the local expression of Dsg1 and Dsg3 is low, and only high concentrations of autoantibodies against desmosomal glycoproteins lead to involvement of the nail in PV [23]. In contrast, Laffitte et al. [24] suggested that expression of Dsg1 and Dsg3 in the periungual skin is disease specific, and autoantibodies against Dsg3 alone may have a role in the development of paronychia in PV.

Clinicians must be aware of unusual nail presentations heralding the occurrence of PV much earlier, as it may pose a diagnostic dilemma and, thus, appropriate treatment may be delayed due to misdiagnosis.

\section{Statement of Ethics}

The patient's consent was obtained.

\section{Disclosure Statement}

The authors have no conflicts of interest to disclose.

References

Skin Appendage Disord 2017;3:28-31 DOI: $10.1159 / 000455881$
1 Champion R, Burton J, Burns D, et al: Textbook of Dermatology, ed 6. Oxford, Blackwell Science, 1998, pp 1849-1855.

2 Eyre R, Stanley J: Identification of pemphigus vulgaris antigen extracted from normal human epidermis and comparison with pemphigus foliaceus antigen. J Clin Invest 1988; 81:807-812.

3 Sampaio S, Rivitti E: Dermatologia, ed 2. São Paulo, Artes Médicas, 2000, pp 229-248.

4 Martins C, Squiquera H, Diaz L: Pemphigus vulgaris and pemphigus foliaceus. Curr Probl Dermatol 1989;1:33-61. 
5 Engineer L, Norton L, Ahmed R: Nail involvement in pemphigus vulgaris. J Am Acad Dermatol 2000;43:529-535.

6 Schlesinger N, Katz M, Ingber A: Nail involvement in pemphigus vulgaris. Br J Dermatol 2002;146:836-839.

7 El-Komy MM, Abdel Halim DM, Samir N, Hegazy RA, Gawdat HI, Shoeb SA: Nail changes in female pemphigus vulgaris patients on immunosuppressive therapy. Int J Womens Dermatol 2015;1:82-84.

8 Kim BS, Song KY, Youn J, Chung JH: Paronychia - a manifestation of pemphigus vulgaris. Clin Exp Dermatol 1996;21:315-317.

9 Rivera Diaz R, Alonso Llamazares J, Rodriguez Peralto JL, Sebastian Vanaclocha F, Iglesias Diez L: Nail involvement in pemphigus vulgaris. Int J Dermatol 1996;35:581-582.

10 Akiyama C, Sou K, Furaya T, Saitoh A, Yasaka N, Ohtake N: Paronychia - a sign heralding an exacerbation of pemphigus vulgaris. J Am Acad Dermatol 1993;129:461-464.

11 Dhawan SS, Zaias N, Pena J: The nail fold in pemphigus vulgaris. Arch Dermatol 1990; 126:1374-1375.
12 Lee HE, Wong WR, Lee MC, Hong HS: Acute paronychia heralding the exacerbation of pemphigus. Int J Clin Pract 2004;58:11741176

13 De Berker D, Daalziel K, Dawber RPR, et al: Pemphigus associated with nail dystrophy. $\mathrm{Br}$ J Dermatol 1993;129:461-464.

14 Parameswara Y, Naik R: Onychomadesis associated with pemphigus vulgaris. Arch Dermatol 1981;117:759-760.

15 Baumal A, Robinson M: Nail bed involvement in pemphigus vulgaris. Arch Dermatol 1973;107:751.

16 Fulton R, Campbell I, Carlyle D, et al: Nail bed immunofluorescence in pemphigus vulgaris. Acta Derm Venereol 1983;63:170-172.

17 Leroy D, Lebrun J, Maillard V, et al: Pemphigus végétant a type clinique de dermatite pustuleuse chronique de hallopeau. Ann Dermatol Venereol 1982;109:549-555.

18 Stone O, Mullins J: Vegetative lesions in pemphigus. Dermatol Int 1966;5:137-140.
19 Ito T, Ito N, Saathoff M, Stampachiacchiere B, Bettermann A, Bulfone-Paus S, et al: Immunology of the human nail apparatus: the nail matrix is a site of relative immune privilege. J Invest Dermatol 2005;125:1139-1148.

20 Kolivras A, Gheeraert P, Andre J: Nail destruction in pemphigus vulgaris. Dermatology 2003;206:351-352.

21 Habibi M, Mortazavi H, Shadianloo S, Balighi K, Ghodsi SZ, Daneshpazhooh M, Valikhani M, Ghassabian A, Pooli AH, Chams-Davatchi C: Nail changes in pemphigus vulgaris. Int J Dermatol 2008;47:1141-1144.

22 Reich A, Wiśnicka B, Szepietowski JC: Haemorrhagic nails in pemphigus vulgaris. Acta Derm Venereol 2008;88:542.

23 Carducci M, Calcaterra R, Franco G, Mussi A, Bonifati C, Morrone A: Nail involvement in pemphigus vulgaris. Acta Derm Venereol 2008;88:58-60.

24 Laffitte E, Panizzon RG, Borradori L: Orodigital pemphigus vulgaris: a pathogenic role of anti-desmoglein-3 autoantibodies in pemphigus paronychia? Dermatology 2008;217:337339. 